\title{
Mecanismos formales e informales para el reconocimiento de nuevos derechos y la disfuncionalidad del sistema interamericano de derechos humanos
}

Formal and informal mechanisms to recognize new rights and the disfunctionality of the Inter-American System of Human Rights

Ariel Dulitzky

Universidad de Texas, Austin

Karina G. Carpintero

Pontificia Universidad Católica Argentina

\section{Resumen}

El reconocimiento de nuevos derechos y estándares de derechos humanos en el ámbito del Sistema Interamericano de Derechos Humanos ha seguido distintas lógicas. En este artículo categorizamos mecanismos formales e informales a partir de un estudio del marco jurídico interamericano y la jurisprudencia de sus órganos. Este análisis crítico pretende reflexionar sobre el avance de estos mecanismos dentro del sistema interamericano y su discutida legitimidad democrática.

\section{Palabras clave}

Sistema Interamericano de Derechos Humanos / Derechos Humanos.

\section{Summary}

The acknowledgement of new rights and human rights standards in the context of the InterAmerican System of Human Rights had followed different logics. This paper categorizes formal and informal mechanisms regarding the inter-american legal framework and the jurisprudence of its organs. Here we propose a critical analysis of the progress of the interamerican system of human rights' mechanisms and its debated democratic legitimacy.

\section{Keywords}

Inter-American System of Human Rights / Human Rights.

\section{Introducción}

La Convención Americana sobre Derechos Humanos (en adelante $\mathrm{CADH}$ ) ha contribuido a institucionalizar el reconocimiento de derechos humanos en América Latina y el Caribe. A través de este tratado, se crearon mecanismos jurisdiccionales de protección de derechos, que acompañaron las transiciones hacia la democracia y la instauración de un núcleo de derechos humanos inderogables. Desde su aprobación en 1969, se han producido distintas transformaciones, que no han sido necesariamente uniformes o sistemáticas, en el proceso interamericano de reconocimiento de derechos humanos en América Latina y el Caribe. De modo contrario, los mecanismos de creación de nuevos derechos han seguido distintas lógicas, que aquí distinguiremos entre formales e informales. Previo a llegar a esta cuestión, que hace al punto central de este artículo, es interesante recordar el contexto de aquel entonces.

La CADH, aprobada en 1969 se mostró permeable para acompañar los distintos cambios sociales e institucionales del hemisferio. El Sistema Interamericano y, en particular, 
la Convención Americana se adecuaron flexiblemente a realidades diferentes a través de la creación de nuevos derechos o la expansión de los ya reconocidos, de la mano de la adopción de nuevos tratados, la jurisprudencia de la Corte Interamericana de Derechos Humanos (en adelante $\mathrm{CIDH}$ ), la práctica de la Comisión Interamericana de Derechos Humanos (en adelante la Comisión) y la justicia constitucional latinoamericana. Ahora bien, en esta carrera por el reconocimiento de nuevos derechos y la elevación del umbral de protección que ofrece la $\mathrm{CADH}$, la evolución que propusieron los organismos regionales se ha presentado eminentemente asistemática. Caracterizamos como asistemático este devenir interamericano por la falta de criterios predecibles en cuanto a cómo y cuándo se crean nuevos derechos o se expanden los existentes. Así, hay casos individuales que toman la forma de estándar regional o que ordenan reformar constituciones sin basarse en textos convencionales claros. Se adoptan convenciones interamericanas especializadas en lugar de reformar o pensar en protocolos a la CADH. Estas convenciones especializadas muchas veces son utilizadas luego por la $\mathrm{CIDH}$ sólo para complementar argumentaciones, pero no para desarrollar nuevos y mejores estándares especializados. Del mismo modo, se extienden los derechos, supuestamente, bajo un dialogo jurisprudencial con las altas cortes de América Latina y el Caribe que tiende a ser algo más parecido a un monólogo unidireccional de la Comisión.

El propósito de este artículo es contribuir al debate sobre si la existencia de canales más sistemáticos de creación de nuevos derechos en el ámbito del Sistema Interamericano de Derechos Humanos podría mejorar la legitimidad en el proceso de creación de derechos y con ello mejorar su protección en la región. Para formular dicha proposición dividimos este artículo en tres secciones. En la primera sección, presentamos los mecanismos formales de ampliación de derechos. Con esta expresión, nos referiremos a las acciones que habilita la propia CADH mediante sus previsiones 76 y 77 , protocolos y enmiendas. En la segunda sección, distinguimos los mecanismos informales como otra forma de ampliar derechos. Esta diferenciación con los mecanismos formales se debe a que no surgen específicamente del tratado interamericano (hoja de ruta del sistema interamericano y rectora de sus órganos jurisdiccionales). Por eso, incluimos en este alcance, a las convenciones interamericanas especializadas en distintos derechos y la interpretación que ha realizado la CIDH mediante su jurisprudencia, así como la de los tribunales nacionales. En la cuarta y última sección, compartimos una reflexión final.

\section{Mecanismos formales de ampliación de derechos}

Denominamos mecanismos formales de ampliación de derechos a los procedimientos de reforma establecidos en la CADH. Dicho tratado, prevé dos disposiciones para la creación de nuevos derechos, los Artículos 76 y 77 (incisos 1 y 2).

El Artículo 76 prevé la reforma de la Convención a través de enmiendas. Este artículo debe ser complementado con el Artículo 31 de la Convención que dispone "podrán ser incluidos en el régimen de protección de esta Convención otros derechos y libertades que sean reconocidos de acuerdo con los procedimientos establecidos en los Artículos 76 y 77 ”. No obstante, el Artículo 76 no ha sido aplicado; es decir, no se han realizado enmiendas a la Convención, y por lo tanto es difícil saber cuál es la interpretación adecuada del Artículo 76 de la $\mathrm{CADH}$.

Para comprender mejor el Artículo 76 de la $\mathrm{CADH}$, es importante destacar que el primer párrafo se refiere a la Asamblea General y a la Secretaría General, dos órganos pertenecientes a otro tratado, la Carta de la OEA. Respecto a la Asamblea General, ella está integrada por representantes de todos los Estados miembros de la OEA, algunos de los cuales 
no son Estados Parte de la Convención. En la misma sección, se expresa que la propuesta de enmienda debe ser sometida a la Asamblea General "para lo que estime conveniente"; no se determina si es la propia Asamblea General o la Asamblea de Estados Parte la que debe decidir sobre la propuesta de enmienda.

El segundo párrafo del Artículo 76 de la $\mathrm{CADH}$ estipula la entrada en vigor de las enmiendas sólo para los Estados ratificantes de las mismas. Así, genera la posibilidad de obligaciones y derechos distintos, según se trate de Estados ratificantes o no de dicha enmienda (Arrighi, 1998). Con ello, podría haber derechos vigentes para algunos Estados, pero no para otros.

En el único precedente donde existe una propuesta de enmienda a la Convención, es en un caso realizado por Nicaragua. La Asamblea General decidió solicitar a todos los Estados miembros de la OEA su opinión para que sea considerada luego por los Estados Parte de la Convención. La propuesta nicaragüense nunca fue discutida y aprobada por los Estados Parte (Arrighi, 1998).

Complementariamente, el Artículo 77 prevé la posibilidad de incluir otros derechos a través de protocolos adicionales a la $\mathrm{CADH}$ "con la finalidad de incluir progresivamente en el régimen de protección de la misma otros derechos y libertades”. A diferencia del procedimiento previsto en el Artículo 76, ha habido dos protocolos a la Convención adoptados en función del Artículo $77^{1}$. Este precepto prevé, a diferencia del Artículo 76, que las propuestas de protocolos serán sólo sometidas a "consideración de los Estados Partes" y no de todos los Estados miembros de la OEA. El caso que prevé el Artículo 77 fue utilizado en distintas oportunidades.

El primer protocolo adoptado fue el Protocolo Adicional a la Convención Americana sobre Derechos Humanos en Materia de Derechos Económicos, Sociales y Culturales (en adelante "Protocolo de San Salvador"). El Protocolo se origina en una propuesta sometida por la Comisión que fue considerada y adoptada por la Asamblea General reunida en San Salvador, El Salvador, de allí su nombre. Es importante destacar que el Protocolo fue aprobado por la Asamblea General de la OEA y no por los Estados Partes de la Convención como lo dispone el Artículo 77. El Protocolo de San Salvador fue acogido, de acuerdo a su Preámbulo, con el objetivo de que los derechos económicos, sociales y culturales "sean reafirmados, desarrollados, perfeccionados y protegidos". Por tanto, es un instrumento regional especializado que protege de manera directa el derecho a la salud, a un medio ambiente sano, a la alimentación, a la educación, al trabajo, a condiciones de trabajo justas y equitativas, derecho a la sindicalización, seguridad social, los beneficios de la cultura, y la protección especial de la familia, los niños, los ancianos y las personas con discapacidad (Melish, 2008, p. 239). La CIDH ha entendido que el Protocolo recoge "avances en el desarrollo de los derechos humanos en el continente" (CIDH, 2009a, Kawas Fernández Vs. Honduras, párrafo 148). Sin embargo, hasta el momento, la CIDH no ha determinado la relación entre el Protocolo y el Artículo 26 de la Convención que se refiere a los derechos económicos, sociales y culturales. Tampoco ha explicado cuál es la relación entre los derechos contenidos en el Protocolo con los emergentes de la Declaración Americana de los Derechos y Deberes del Hombre.

Respecto del tratamiento que pueda ofrecer la CIDH en cuanto al Protocolo de San Salvador, vale decir que su Artículo 19.6, dispone que el tribunal interamericano sólo puede ejercer su función contenciosa en caso de violación del derecho a la educación (Artículo 8) y libertad sindical (Artículo 13). No obstante, la CIDH ha utilizado e interpretado el Protocolo de San Salvador en diferentes contextos. Esto refleja que el Protocolo contiene

${ }^{1}$ A diferencia de la americana, la Convención Europea de Derechos Humanos tiene 16 Protocolos. 
disposiciones sustantivas sobre los derechos protegidos y que extiende, aunque limitadamente, la competencia de la Comisión y la CIDH.

Inicialmente, la CIDH había considerado al Protocolo para "fijar el contenido y alcance" de otros artículos de la Convención (CIDH, 2004c, Instituto de Reeducación del Menor Vs. Paraguay, párrafos 148 y 172). También había entendido que el Protocolo a veces "recoge la misma idea y precisa" el contenido de derechos genéricos contemplados en la Convención (CIDH, 2001, Baena Ricardo y otros Vs. Panamá, párrafo 159). De hecho, en virtud del Artículo 29 de la Convención, el Tribunal ha utilizado el Protocolo para extender o precisar el alcance de ciertos derechos de la Convención (CIDH, 2012d, Artavia Murillo y otros Vs. Ecuador, párrafos 150 y 122). Incluso, ha utilizado el Protocolo para analizar las limitaciones permisibles de derechos reconocidos en la Convención y refiriéndose a artículos del Protocolo que no figuran mencionados en el Artículo 19.6 del Protocolo sobre casos individuales y la competencia de la CIDH (CIDH, 2003, “Cinco pensionistas”Vs. Perú, párrafo 116).

Recién, en 2015, en la sentencia dictada en el caso Gonzales Lluy Vs. Ecuador (CIDH, 2015), la CIDH hace, por primera vez, un pronunciamiento directo de la violación al Protocolo de San Salvador. La CIDH se pronunció en cuanto al derecho a la educación (Artículo 13) en relación con los Artículos 19 y 1.1 de la Convención Americana en perjuicio de Talía Gonzales Lluy. Esto marcó un punto de inflexión en la jurisprudencia del tribunal interamericano (CIDH, 2005b, Huilca Tecse Vs. Perú, párrafo 74) al tiempo que suscitó críticas por la forma de utilizar el Protocolo (Ronconi, 2016). El problema fue que la CIDH no se focalizó en la interpretación del Artículo 26 de la $\mathrm{CADH}$, tal como se había argumentado sosteniendo la justiciabilidad de los derechos reconocidos en tal artículo. La CIDH, en cambio, evadió este debate y prefirió aplicar el Protocolo de San Salvador. Ciertamente, es valioso que la $\mathrm{CIDH}$ haya integrado otro instrumento, y que lo haya operacionalizado. Tal camino no es incorrecto, pero es asistemático (en el sentido de no haber analizado la relación entre el Artículo 26 de la Convención y el Protocolo de San Salvador). Queda para otra ocasión esperar que la CIDH dé pautas sobre estas relaciones que resultan esenciales para Estados que han ratificado la Convención y el Protocolo así como aquellos que aún no han ratificado el Protocolo².

El segundo protocolo fue adoptado el 8 de junio de 1990 en la 20va Sesión Ordinaria de la Asamblea General celebrada en Asunción, Paraguay. El protocolo es concerniente a la Abolición de la Pena de Muerte y se origina en una iniciativa uruguaya y un proyecto de la Comisión. En este caso, la Asamblea General sometió el Protocolo a la consideración de los Estados Parte de la Convención (Resolución 0/90 de la Asamblea General AG/RES/0/90). En su preámbulo claramente se indica que el Protocolo significa un "desarrollo progresivo de la Convención Americana sobre Derechos Humanos". El objetivo del Protocolo es "consolidar la práctica de la no aplicación de la pena de muerte dentro del continente americano".

Ahora bien, este protocolo no ha sido interpretado jurisprudencialmente. De hecho, en el marco de uno de los principales estudios sobre pena de muerte en el Sistema Interamericano (Resolución 0/90 de la Asamblea General AG/RES/0/90) el Protocolo apenas es mencionado. Cabe preguntarse, desde la perspectiva de la sistematicidad, si el Protocolo era necesario, cuál era su utilidad y cuáles son los motivos de su subutilización. Al mismo tiempo, es permisible decir que el efecto preventivo de la adopción de este Protocolo ha funcionado y reflejado un consenso regional existente. Simultáneamente, se demuestra, por la falta de casos litigiosos, que dicho consenso no ha sido violado por los Estados ratificantes.

\footnotetext{
${ }^{2}$ Los países signatarios del protocolo de San Salvador que aún no han ratificado son Brasil, Chile, Colombia, Honduras y Surinam.
} 


\section{Mecanismos informales de ampliación de derechos}

El hecho de que existan mecanismos formales para ampliar el catálogo de derechos que consagra la Convención, no ha significado que se les haya dado algún uso. A modo contrario, la expansión de derechos se ha dado a través de mecanismos eminentemente informales. Como tales, consideramos (a) la adopción de convenciones interamericanas y (b) la interpretación de la CIDH Interamericana en su jurisprudencia. La distinción entre la adopción de nuevas convenciones y la expansión jurisprudencial es esencial pues la voluntad estatal continúa presente ( $\mathrm{y}$ en esto se acerca a los procedimientos formales de la sección anterior). En el segundo supuesto, la voluntad estatal queda relegada a la mera presentación de argumentos que la CIDH puede aceptar, rechazar o ignorar. De nuevo, la asistematicidad, se encuentra presente ya que no hay un criterio definido. Es una dinámica que se define caso a caso.

\subsection{Adopción de nuevas de convenciones interamericanas}

Para reconocer nuevos derechos, la OEA ha adoptado varios tratados relativos a los derechos humanos con posterioridad a la Convención. Esto podría entenderse como un franco desconocimiento del mecanismo de enmiendas o de protocolos adicionales (Artículos 76 y $77 \mathrm{CADH}$ ). De otro lado, podría considerarse que esto implica ofrecerle un estatus más fuerte a nuevos derechos, en clara conexión con ciertos fenómenos sociales (por ejemplo, discriminación racial, adultos mayores, personas con discapacidad, tortura, etc). Otra alternativa, es que se trate de un intento de expandir la protección de derechos dada la falta de ratificación universal de la Convención ${ }^{3}$. Frente a esto, proponemos dos preguntas para reflexionar sobre esta cuestión.

La primera pregunta que surge es sobre la relación de estos tratados con el contenido de la Convención. Las convenciones interamericanas posteriores a la $\mathrm{CADH}$, ¿son pautas de interpretación del tratado interamericano? ¿Tienen un contenido autónomo y especifico? Estas preguntas ciertamente convocan a muchas otras vinculadas con la interpretación de los tratados. La Convención debe ser interpretada de conformidad con las reglas generales que la Convención de Viena señala para los tratados internacionales, y con las reglas especiales que surgen de su naturaleza misma de ser un tratado sobre derechos humanos (Aguirre, 2007). La interpretación de los tratados internacionales se encuentra regulada tanto a través de normas consuetudinarias como de normas convencionales, particularmente a través de la Convención de Viena sobre Derechos de los Tratados de 1969. Los Artículos 31 y 32 de dicho instrumento establecen los medios de interpretación aplicables a los tratados internacionales. Adicionalmente, la Conferencia Preparatoria de la Convención Americana adoptó el Artículo 29 que establece criterios de interpretación específicos para la Convención. En ese sentido, al interpretar un tratado de derechos humanos, debe tenerse presente esta diferencia y no aplicar sin más el Artículo 31 de la Convención de Viena de 1969.

La CIDH ha aplicado el Artículo 29 de la CADH para precisar el contenido de ciertas disposiciones de la Convención. Mediante su práctica interpretativa, la $\mathrm{CIDH}$ ha observado las directrices establecidas en el Artículo 29 de la CADH y en la Convención de Viena. Además, ha tomado en consideración la naturaleza y los valores comunes superiores en que se inspira la Convención. De este modo, por vía del Artículo 29, la CIDH ha ampliado derechos y, a través de distintas fuentes del derecho internacional de derechos humanos, los ha dotado de contenido.

\footnotetext{
${ }^{3}$ Ver Corte Interamericana de Derechos Humanos. Consideraciones sobre la ratificación universal de la Convención Americana y otros tratados interamericanos en materia de derechos humanos. OAS <http://www.oas.org/es/cidh/informes/ pdfs/Universalizacion-sistema-interamericano.pdf>.
} 
Lo que el sistema no ha definido aún es la relación orgánica entre la Convención y los tratados interamericanos. Este vacío jurisprudencial deja pendiente la determinación de cómo dialogan, como partes de un mismo engranaje, este conjunto de convenciones dentro del Sistema Interamericano de Derechos Humanos. Es decir, como interactúan para la real evolución de los derechos humanos y no supeditados a lo que un caso concreto demanda. Por ejemplo, si hay discrepancias entre el contenido de uno y otro tratado, ¿cuál debería prevalecer?, ¿se aplicará el principio de norma posterior deroga norma anterior, el principio de especialidad o el principio pro persona?

De todas maneras, para muestra de la asistematicidad de la expansión de derechos, en la vasta mayoría de casos en que la $\mathrm{CIDH}$ ha utilizado tratados interamericanos diferentes a la Convención, tampoco ha explicado cuáles son las obligaciones diferenciadas o cuáles son los nuevos derechos reconocidos o el alcance expandido de los derechos reconocidos en estos tratados4. Es decir, ¿qué adicionan los tratados subsecuentes a la Convención? Hasta el momento, la jurisprudencia no ha dado respuesta específica a estos interrogantes, aunque si ha dado ciertas pautas como veremos en los próximos capítulos.

La segunda pregunta es ¡cuáles son las posibilidades de accionar los mecanismos de protección jurisdiccional previstos por la $\mathrm{CADH}$ para invocar violaciones a los derechos reconocidos en estas convenciones adicionales? Al respecto, será preciso observar cada una de las convenciones para analizar si igualmente habilitan la jurisdicción contenciosa de la Comisión y a la CIDH para analizar peticiones que aleguen violaciones de tales convenciones.

En el caso de la Convención Interamericana para Prevenir y Sancionar la Tortura, se incluye una detallada definición de la tortura, así como de los deberes que le corresponde a los Estados y los derechos para las víctimas de la tortura; no obstante, su alcance ha sido definido a través del Artículo 29 de la CADH (Mac-Gregor, 2014). Respecto de los mecanismos de protección, si se establece su relación con la $\mathrm{CADH}$ no se explicita si se pueden presentar denuncias a la Comisión y eventualmente a la CIDH por violaciones a la Convención sobre Tortura. Ahora bien, la CIDH ha explicado que la Convención Interamericana refuerza las obligaciones que emergen de los Artículos 5.1 y 5.2 de la Convención (CIDH, 2012e, Masacres de El Mozote y lugares aledaños Vs. El Salvador, párrafo 243). Asimismo, agrega el Tribunal que la Convención Interamericana "complementa, en lo pertinente, la obligación de adoptar las disposiciones necesarias para hacer efectivos los derechos convencionales, establecido en el Artículo 2 de la Convención Americana" (CIDH, 2013b, García Lucero y otros Vs. Chile, párrafo 87). De todas maneras, ni las conclusiones ni las reparaciones que el Tribunal ordena difieren de casos de tortura en los cuales el Estado no ha ratificado la Convención Interamericana sobre Tortura. Es decir, no es evidente cómo "refuerza" o "complementa" a la Convención Americana.

En el caso de la Convención Interamericana para Prevenir, Sancionar y Erradicar la Violencia contra la Mujer "Convención de Belem do Para" el Artículo 14 regula la relación con la CADH. Estipula que nada de lo dispuesto en ella puede ser interpretado como restricción o limitación a la Convención Americana o a otras convenciones internacionales sobre la materia que prevean iguales o mayores protecciones.

\footnotetext{
${ }^{4}$ Un caso reciente que ejemplifica esta cuestión es Pueblo Kaliña. En este caso, al introducirse la CIDH en cuestiones de comunidades indígenas y medio ambiente, y de revisarse las notas al pie del párrafo 283 se detectan una serie de tratados internacionales, declaraciones, directrices que no van acompańados de un razonamiento que dé cuenta de algún tipo de implementación por parte del tribunal interamericano. Ver Corte Interamericana de Derechos Humanos (2015) Pueblos Kaliña y Lokono Vs. Surinam. Fondo, Reparaciones y Costas. Sentencia de 25 de noviembre de 2015. Serie C No. 309.
} 
A su vez, el articulo 12 permite que "cualquier persona o grupo de personas, o entidad no gubernamental [...], puede presentar a la CIDH [...] peticiones que contengan denuncias o quejas de violación del Artículo 7 de la presente Convención por un Estado Parte, y la CIDH las considerará de acuerdo con las normas y los requisitos de procedimiento para la presentación y consideración de peticiones estipulados en la Convención Americana [...] y en el Estatuto y el Reglamento de la CIDH [...]. En otras palabras, para llegar a la CIDH e invocar la Convención de Belem do Para, se necesita haber ratificado la CADH y aceptado la jurisdicción contenciosa del Tribunal. En adición a este criterio, la CIDH ha estipulado que al aplicar la Convención en situaciones de violencia contra la mujer debe considerarse "como referencia de interpretación las disposiciones pertinentes de la Convención de Belem do Pará” (CIDH, 2009b, Ríos y otros Vs. Venezuela, párrafo 277).

Asimismo, en relación a las posibilidades de accionar los mecanismos de protección, la CIDH entendió que "tras la entrada en [vigencia...] de la Convención Belém do Pará [...], el Estado está obligado a utilizar la debida diligencia para prevenir, sancionar y erradicar la violencia contra la mujer. [...L] as disposiciones del Artículo 7.b de la Convención de Belém do Pará especifican y complementan las obligaciones que tiene el Estado con respecto al cumplimiento de los derechos consagrados en la Convención" (CIDH, 2013a, J. Vs. Perú, párrafo 342).

A su turno, la Convención Interamericana sobre Desaparición Forzada de Personas 5 define que "la desaparición forzada de personas viola múltiples derechos esenciales de la persona humana de carácter inderogable”. La CIDH ha interpretado que esta Convención Interamericana particulariza (CIDH, 2010b, Ibsen Cárdenas e Ibsen Peña Vs. Bolivia, párrafo 67) o refleja (CIDH, 2008b, Tiu Tojín Vs. Guatemala, párrafo 52) las características pluriofensivas de la desaparición forzada, su carácter permanente o continuado, así como los deberes de investigación. Todas estas características ya estaban aceptadas explícita o implícitamente por la CIDH sin utilizar este nuevo tratado. Tampoco ha especificado jurisprudencialmente las diferencias entre las obligaciones genéricas emergentes de la $\mathrm{CADH}$ y las específicas de la de Desaparición Forzada (Brody \& González, 1997, pp. 365-405).

En cuanto a las formas de accionar los mecanismos de protección de la $\mathrm{CADH}$, el Artículo XIII de la Convención Interamericana sobre Desaparición Forzada de Personas dispone que el trámite de las peticiones o comunicaciones presentadas ante la $\mathrm{CIDH}$, en que se alegue la desaparición forzada de personas, estará sujeto a los procedimientos establecidos en la Convención Americana y en los Estatutos y Reglamentos de la CIDH y de la CIDH, incluso las normas relativas a medidas cautelares.

En el caso de la Convención Interamericana para la Eliminación de todas las formas de Discriminación contra las Personas con Discapacidad, la $\mathrm{CIDH}$ la ha utilizado para indicar el ámbito de protección de las personas con discapacidad en el caso Furlan Vs. Argentina. En tal sentido, ha reconocido que las personas con discapacidad tienen los mismos derechos humanos y libertades fundamentales que otras personas; y que estos derechos, incluido el de no verse sometidos a discriminación fundamentada en la discapacidad, dimanan de la dignidad y la igualdad que son inherentes a todo ser humano. Asimismo, dicha Convención consagró un catálogo de obligaciones que los Estados deben cumplir con el objetivo de alcanzar "la prevención y eliminación de todas las formas de discriminación contra las personas con discapacidad y propiciar su plena integración en la sociedad" (CIDH, 2012b, Furlan y Familiares Vs. Argentina, párrafo 130). En particular, en el caso Furlan Vs. Argentina,

\footnotetext{
${ }^{5}$ Ver Scovazzi, T. y Citroni G. (2007). The struggle against enforced disappearance and the 2007 United Nations convention. Leiden: Martinus Hijhoff Publishers.
} 
el Tribunal utilizó la Convención sobre Discapacidad para definir el concepto de modelo social y término discapacidad en el contexto de este paradigma (CIDH, 2012b, Furlan y Familiares Vs. Argentina, párrafo 130). Ahora bien, es importante resaltar que, a diferencia de todas las demás convenciones sobre derechos humanos adoptadas con posterioridad a la Convención, este tratado no establece ningún mecanismo de protección vinculado con las competencias de la CIDH o la CIDH.

En lo tocante a la Convención Interamericana contra Toda Forma de Discriminación e Intolerancia y la Convención Interamericana contra El Racismo, la Discriminación Racial y Formas Conexas de Intolerancia, ambas convenciones fueron adoptadas conjuntamente por la OEA en 2013 pero hasta la fecha, ninguna de ellas ha sido ratificada por algún Estado.

En adición a la posibilidad de presentar denuncias individuales a la $\mathrm{CIDH}$, un aspecto importante de estas Convenciones es que amplían la jurisdicción de la $\mathrm{CIDH}$ al permitir en su Artículo 15.3 que se acepte la competencia del Tribunal sólo para aplicar estas convenciones, pero no requiriéndose que sea parte de la Convención Americana. Ello presenta un modelo completamente diferente a todas las convenciones previas.

En cuanto a la Convención Interamericana sobre la Protección de los Derechos Humanos de las Personas Mayores, esta Convención de manera novedosa acepta la posibilidad de presentar denuncias individuales, es decir la competencia contenciosa de la CIDH Interamericana sin ratificar la $\mathrm{CADH}$, y toma el modelo de las Convenciones sobre Racismo y la de Discriminación al ampliar la jurisdicción de la $\mathrm{CIDH}$.

\subsection{La ampliación de derechos a través de la jurisprudencia}

En conjunto con las formas convencionales previstas en los Artículos 31, 76 y 77 de la Convención o la adopción de tratados adicionales por parte de la OEA, múltiples derechos han sido agregados a la Convención a través de la jurisprudencia de la $\mathrm{CIDH}$. "[L]a Corte interamericana fue reescribiendo la Convención Americana tanto en aspectos relacionados con los derechos de la persona, como en asuntos referidos a la competencia y función del tribunal: ella creó nuevas reglas o nuevos derechos humanos o modificó algunos existentes" (Malarino, 2010).

El activismo judicial de la CIDH le ha permitido crear nuevos derechos que no están expresamente contenidos o protegidos por la Convención como el derecho a la verdad (CIDH, 2004a, Carpio Nicolle y otros Vs. Guatemala, párrafo 128) o el derecho de conocer la verdad (CIDH, 2004b, Masacre Plan de Sánchez Vs. Guatemala, párrafo 97), el derecho a la consulta previa de los pueblos y comunidades indígenas y tribales (CIDH, 2012c, Pueblo Indígena Kichwa de Sarayaku Vs. Ecuador, párrafos 301-302), el derecho a la identidad (CIDH, 2011, Contreras y otros Vs. El Salvador, párrafo 112), entre otros (CIDH, 2010, Chitay Nech y otros Vs. Guatemala, párrafos 164 y siguientes). Ninguno de estos derechos se encuentra, ni explicita ni expresamente, reconocido en la CADH.

Esta creación de derechos acarrea deberes para los Estados que incluyen una "expectativa que el Estado debe satisfacer" (CIDH, Sánchez Vs. Guatemala, párrafo 97), un deber de "garantía de no repetición" (CIDH, Sánchez Vs. Guatemala, párrafo 97), la obligación de "adoptar las medidas legislativas, administrativas o de otra índole que sean necesarias para poner plenamente en marcha y hacer efectivo, en un plazo razonable", el derecho creado (CIDH, Sánchez Vs. Guatemala, párrafo 97).

Esta situación ha generado críticas a la legitimidad de la jurisprudencia de la $\mathrm{CIDH}$ (Basch, 2013). Se sostiene que la creación jurisprudencial de derechos no refleja ni la práctica estatal ni el consenso regional, a la par que avanza sobre la voluntad estatal 
creando obligaciones jurídicas muchas veces a partir de normas de derecho blando (soft law) o importadas de otras regiones (Neuman, 2008). Varios autores han llamado la atención sobre los riesgos asociados con la expansión de las obligaciones convencionales; es decir, cuando el compromiso va más allá de lo que el Estado se encontraba dispuesto a aceptar en el momento que ratificó el tratado (Helfer, 2002). Compartimos la crítica que se le formula al Tribunal sobre la debilidad argumentativa utilizada al "crear" nuevos derechos. Pero dejamos para otra ocasión el desarrollo de nuestra posición sobre la legitimidad o inteligencia de estas creaciones pretorianas. También, obviamos analizar si lo que realiza la CIDH es diferente a la actividad propia de cualquier órgano jurisdiccional.

En lo sucesivo, detectamos las maneras que ha utilizado el tribunal interamericano en el afán del crear derechos de manera informal: (1) la incorporación de otros derechos a través del corpus iuris, (2) la definición de normas dentro del ius cogens (3) la creación de derechos a través de la interpretación evolutiva de la Convención Americana y (4) el diálogo transnacional.

\subsubsection{La incorporación de otros derechos a través del corpus iuris}

Una de las maneras en que la CIDH (seguida luego por la Comisión) ha ampliado el catálogo de derechos y obligaciones de la Convención ha sido a través de la incorporación en su texto de otros tratados mediante el concepto de "corpus iuris" (la Comisión, 1999). La CIDH y la Comisión han aplicado esta noción de corpus iuris de forma reiterada y consistente en sus decisiones para fijar los alcances de las obligaciones de los Estados en relación a ciertos derechos (en particular, pero no exclusivamente, los derechos de la niñez). En general, el Tribunal ha entendido que el corpus iuris debe servir para fijar (CIDH, 2012, Fornero E hija Vs. Argentina, párrafo 137) o precisar (CIDH, 2005a, Masacre de Mapiripán Vs. Colombia, párrafo 153) el contenido y los alcances de la disposición general de la Convención. La $\mathrm{CIDH}$, a pesar de tener competencia sólo para aplicar la Convención, llama a que dicho corpus iuris internacional sea respetado por los Estados (CIDH, 2005a, Masacre de Mapiripán Vs. Colombia).

La amplitud con que el Sistema Interamericano ha utilizado este concepto de corpus iuris le ha permitido a la CIDH encontrar violaciones de derechos que ni siquiera están expresamente reconocidos en la Convención (CIDH, 2011, Contreras y otros Vs. El Salvador, párrafo 112). Así, la CIDH, a través del corpus iuris, incorpora un derecho reconocido en otro instrumento, pero no en la Convención, y determina su afectación. Esta amplitud interpretativa de la CIDH genera muchas dudas pues, a través del corpus iuris, se incorporan obligaciones y derechos que emergen de otros regímenes. Se establecen violaciones sobre tratados sobre los cuales la CIDH no tiene competencia o jurisdicción. Al recurrir como pauta de interpretación a instrumentos distintos a tratados debidamente ratificados por el Estado, se incorporan obligaciones jurídicas de instrumentos que no son jurídicamente vinculantes para los Estados.

Entonces, de la utilización del corpus iuris y otras técnicas expansivas podría inferirse que la CIDH no crea nuevos derechos, sino que simplemente agrega nuevas dimensiones a derechos preexistentes. No obstante, es razonable la afirmación sobre las notables excepciones a estos casos, supuestos donde incluso se han adicionado dimensiones colectivas a los derechos (Lixinski, 2010, p. 603).

El problema del corpus iuris no es la utilización de otros tratados con fines interpretativos ya que puede ser necesario utilizarlos para dilucidar el contenido de la Convención. El problema surge cuando los tratados son utilizados sin un análisis detallado; 
existe un conflicto cuando se los emplea como si fuesen directamente aplicables por la CIDH o como si el lenguaje utilizado fuese idéntico al de la Convención o como si la existencia de órganos especializados para aplicarlos fuese irrelevante (Paul; 2014). Otro problema reside en el hecho que la CIDH a veces utiliza tratados, como parte del corpus iuris, ratificados por el Estado pertinente pero luego cita su decisión en relación a Estados que no ratificaron el tratado respectivo ${ }^{6}$. A nuestro criterio, la supuesta apertura universalista, integracionista de la $\mathrm{CADH}$ no es suficiente para integrar tratados adoptados en otros sistemas como si fuesen parte integral de la Convención.

\subsubsection{La definición de derechos como normas ius cogens}

En el marco de su jurisdicción contenciosa, la CIDH ha elevado ciertos derechos convencionales a la categoría de normas ius cogens ${ }^{7}$. Cuando ha procedido de este modo, si bien no crea nuevos derechos, si les da un estatus especial del cual se derivan consecuencias jurídicas importantes para los Estados (Quispe Remon, 2010) ${ }^{8}$. Del mismo modo, ha establecido que el "acceso a la justicia constituye una norma imperativa de Derecho Internacional y, como tal, genera obligaciones erga omnes para los Estados de adoptar las medidas que sean necesarias para no dejar en la impunidad esas violaciones" (CIDH, 2006, La Cantuta Vs. Perú, párrafo 160).

Por supuesto que, si la CIDH determinara la existencia de normas imperativas de derecho internacional como las reflejadas en la Convención, no habría ninguna dificultad. El problema con esta práctica expansiva de la $\mathrm{CIDH}$ es que muchas de sus determinaciones sobre normas ius cogens se realizan sin ningún tipo de prueba o lógica argumental. Por el contrario, generalmente son afirmaciones dogmáticas del Tribunal interamericano. La invocación del carácter ius cogens de ciertos derechos, al igual que otras técnicas utilizadas por la CIDH, implica que el consentimiento estatal es irrelevante en tanto y en cuanto no puede oponerse a su aplicación (Fuentes, 2008). Aquí, la asistematicidad de la CIDH se da no sólo al interior del Sistema Interamericano sino incluso en relación al derecho internacional en general. Ello pues el Tribunal se arroga la facultad de crear normas imperativas internacionales que repercutirán en toda la comunidad internacional. Hasta ahora, la CIDH no ha explicado de donde emerge su facultad para desarrollar tal jurisprudencia.

\subsubsection{La creación de derechos a través de la práctica interpretativa de la Corte Interamericana de Derechos Humanos}

La CIDH ha ampliado el catálogo de derechos, o al menos el alcance de los derechos reconocidos, a través de lo que ha llamado la interpretación evolutiva (Killander, 2010, p. 149). Es decir, las reglas generales de interpretación de los tratados consagradas en la Convención de Viena de 1969. Los tratados de derechos humanos "son instrumentos vivos, cuya interpretación tiene que acompañar la evolución de los tiempos y las condiciones de vida actuales" (CIDH, 1999a, "Niños de la Calle (Villagrán Morales y otros) Vs. Guatemala, párrafo 193).

\footnotetext{
${ }^{6}$ Como sucedió con el Convenio 169 de la OIT ratificado por Paraguay, pero no por Surinam (CIDH, 2005, Comunidad Indigena Yakye Axa Vs. Paraguay, párrafo 127; CIDH, 2007, Pueblo Saramak Vs. Surinam, párrafos 92 y 93 ).

${ }^{7}$ Para una descripción de los diferentes supuestos en que la CIDH ha elevado normas a la categoría de ius cogens ver Abello, R., (2012) La Jerarquía normativa en la CIDH Interamericana de Derechos Humanos: Evolución jurisprudencial del ius cogens 1993 - 2012, Revista del Instituto Brasileiro de Direitos Humanos 12 (12), 357 - 375.

${ }^{8}$ Ver Almonacid Arellano y otros Vs. Chile (CIDH 2006); CIDH (2003). Condición Jurídica y Derechos de los Migrantes Indocumentados (CIDH, 2011). Fleury y otros Vs. Haití (2010). Chitay Nech y otros Vs. Guatemala (CIDH, 2010a).
} 
Reflejando su experiencia, el propio Tribunal ha indicado que en función de la interpretación evolutiva de la Convención era posible determinar que el derecho a la propiedad comunal de las comunidades indígenas o tribales estaba incluido dentro del derecho a la propiedad privada del Artículo 21. Asimismo, resalta la interpretación de la CIDH según la cual el Artículo 22 de la Convención comprende "el derecho a no ser desplazado forzadamente". Otro ejemplo en este sentido lo constituye el haber interpretado que el derecho de los niños a no ser reclutados en fuerzas o grupos armados está comprendido dentro del Artículo 19 de la Convención (CIDH, 2008a, Apitz Barbera y otros Vs. Venezuela).

Sin embargo, mientras que la interpretación evolutiva puede servir para adecuar la interpretación de la Convención, la propia CIDH reconoce que hay casos donde ha sido utilizada para crear nuevos derechos. Ello genera muchas dudas. Como acertadamente ha indicado el Tribunal Europeo de Derechos Humanos, no es posible por medio de una interpretación evolutiva, derivar de estos instrumentos, un derecho que no estaba incluido originalmente en la Convención (Corte Europea de Derechos Humanos, 1986, Johnston and other Vs. Ireland, párrafo 53).

Dado que la $\mathrm{CIDH}$ no ha encontrado los mismos límites, algunos autores han entendido que esta interpretación evolutiva, en la manera en que es efectuada por la $\mathrm{CIDH}$, es una violación de los Artículos 76 y 77 de la Convención (Malarino, 2010). En otras palabras, es otra manifestación de la actitud expansiva del Tribunal por fuera de los límites formales de su competencia.

\subsubsection{El dialogo transnacional}

Una última forma en que la $\mathrm{CIDH}$ ha ampliado el catálogo de derechos, a través de la interpretación de la Convención, es través del préstamo de fuentes de otros sistemas de protección de derechos humanos (tanto universales como regionales) hasta llegar a fuentes de derecho interno. En esa línea, se puede identificar la utilización de las Observaciones Finales a los Estados por parte del Comité de Derechos Humanos, documentos de procedimientos especiales de la ONU (Dulitzky \& Rivero, 2015) jurisprudencia de otros sistemas regionales de derechos humanos (Groppi \& Lecis, 2014), e incluso las fuentes propias de los estados partes (Dulitzky \& Rivero, 2015, p. 71) (una lista que va desde jurisprudencia, constituciones, leyes nacionales hasta reglamentos procesales).

Un rasgo saliente de estos casos es que, por algún motivo, en ciertas ocasiones, la $\mathrm{CIDH}$ para decidir toma en cuenta las Observaciones Finales del Comité de Derechos Humanos de Naciones Unidas al país sobre el que estaba decidiendo. Es decir, si el caso contencioso a resolver era Honduras, el Tribunal observa qué había dicho el Comité respecto de la situación del país. La CIDH reafirmaba sus interpretaciones jurídicas con las interpretaciones de violación que para ese momento resultaba contemporáneo al caso. Por ejemplo, Masacre de Mapiripán Vs. Colombia (2005a), la CIDH toma las observaciones finales para Colombia del año 2000. Esto no ocurre de forma constante en los casos, pero si es un mecanismo en el que el dialogo jurisprudencial se anima a ser más coherente. Otra ruta que toma la CIDH es la de considerar además de los Pactos Internacionales, la Carta Árabe de Derechos Humanos, la Carta Africana, los convenios de ginebra y otros más tradicionales.

En sentido complementario, la creación de la teoría del control de convencionalidad en 2006, parece marcar un punto de partida en el diálogo jurisprudencial con las cortes locales. Desde entonces, la CIDH incursiona en un tímido uso directo del marco normativo interno; por tanto, emplea tanto leyes ordinarias como constituciones nacionales. En este devenir histórico se produce esta cuarta línea de creación informal de derechos, a través de 
la integración con el derecho nacional. Un ejemplo fue el caso Awas Tingni. En ocasión de definir el derecho a la propiedad comunal en el marco del caso mencionado, el Tribunal tomó en cuenta la definición normativa a nivel interno tomando como base el texto constitucional nicaragüense. Esta última etapa podría llamarse de "integración con el derecho nacional”. Ciertamente, no es una característica estructural de la jurisprudencia de la CIDH (Dulitzky \& Rivero, 2015, p. 51), pero a la hora de validar la creación de nuevos derechos esto sí ha ocurrido. Esta apreciación en los casos citados previamente es notable porque se presentan como herramientas argumentativas. La CIDH ha buscado legitimar su autoridad en otras fuentes a nivel local, ya sea leyes nacionales, reglamentos procesales y las propias constituciones. Especialmente, le ha dado importancia a esa legitimización en circunstancias en las que su interpretación podría suscitar rechazo y que lo que primaba era generar puntos de contacto en el derecho constitucional latinoamericano.

Una pregunta sobre este sucinto recorrido histórico de la jurisprudencia de la CIDH es por qué tuvieron más valor estos cuerpos cuasijurisdiccionales o procedimientos especiales antes que la CIDH. Más aun, visto de esta manera, pareciera que ahora el diálogo con las Cortes locales es un capítulo más de una novela asistemática y difícil de comprender.

\section{Conclusión}

La revisión crítica del marco normativo interamericano formal y los desarrollos jurisprudenciales informales abren muchos interrogantes sobre qué es deseable al momento de reconocer nuevos derechos. Por un lado, es importante contar con una CIDH que avanza frente a las demandas de la sociedad civil, haciendo caso a las violaciones de derechos humanos a nivel regional y reconociendo derechos. Por otro lado, es cuestionable la forma en la que lo hace, considerando que se trata de una corte que no tiene mecanismos de participación ciudadana y que el diálogo jurisprudencial transnacional, con las altas cortes constitucionales o máximos tribunales locales, es escaso y aún embrionario. Como resultado de este devenir, lo que permanece constante son los cuestionamientos hacia la legitimidad de los procedimientos informales.

Frente a esta serie de cuestionamientos, creemos que resulta deseable aspirar a una Corte Interamericana que funcione como parte efectiva de lo que es el Sistema Interamericano de Derechos Humanos. En otras palabras, como parte de un gran engranaje con interlocutores y actores que contribuyen a dicha transformación en la creación de derechos: los Estados miembro (Brody \& González, 1997, pp. 365-405) las cortes locales, la OEA, la sociedad civil y las víctimas de violaciones de derechos humanos. Visto en su conjunto, un debate serio sobre reformar la Convención Americana desde una perspectiva expansiva podría invitar a que muchos Estados vean la propuesta como una oportunidad para partir del sistema. Quizás una salida a estos debates tan estructurales del sistema interamericano, en el contexto actual, venga acompañado de la institucionalización de algunos de los mecanismos informales, como lo es la integración con el derecho nacional, la institucionalización del diálogo transnacional, y el desarrollo de estrategias de reciprocidad entre el tribunal interamericano y las máximas cortes locales. Ahora bien, la forma de alcanzar este objetivo importará a la CIDH incorporar mecanismos de participación ciudadana, que garanticen procedimientos más dialógicos para crear derechos. 


\section{Referencias bibliográficas}

Aguirre, J. (2007). La interpretación de la convención americana sobre derechos humanos. Revista de derechos humanos, 8, 73-97.

Arrighi, J. (1998). El Procedimiento para la Adopción de Enmiendas a la Convención Americana sobre Derechos Humanos. Volumen I. En H. Fix-Zamudio (ed.). Liber Amicorum (pp. 329-340). San José: Corte IDH.

Basch, F. (2013). The Doctrine of the Inter-American Court of Human Rights Regarding States' Duty to Punish Human Rights Violations and Its Dangers. American University International Law Review, 23 (1), 195-229.

Brody, R. y Gonzalez M., (1997). Nunca Más: An Analysis of International Instruments on "Disappearances" Human Rights Quarterly, 19 (2), 365-405.

Dulitzky, A. (2015). An Inter-American Constitutional Court? The Invention of the Conventionality Control by the Inter-American Court of Human Rights. Texas International Law Journal, 75, 45-93.

Dulitzky, A. y Rivero M.D. (2015). Trabajo de orfebrería: Las relaciones entre la CIDH Interamericana de Derechos Humanos y los Procedimientos Especiales del Consejo de Derechos Humanos de las Naciones Unidas. Revista Latinoamericana de Derecho Internacional, 3, 2-46.

Fuentes, X. (2008). International and Domestic Law: Definitely an Odd Couple. Revista Jurídica Universidad de Puerto Rico, 77 (2), 483-505.

Groppi, T. y Lecis A. (2014). Las referencias recíprocas entre el Tribunal Europea y la CIDH Interamericana de Derechos Humanos: ¿¿de la influencia al diálogo? Revista de Derecho Politico, 91, 187-229.

Helger, L. (2002). Overlegalizing Human Rights: International Relations Theory and the Commonwealth Caribbean Backlash Against Human Rights Regimes. Columbia Law Review, 102, 1832-1911.

Killander, M. (2010). Interpretación de los Tratados Regionales de Derechos Humanos. SUR revista internacional de derechos humanos, 7 (13), 149-176.

Lixinski, L. (2010). Treaty Interpretation by the Inter-American Court of Human Rights: Expansionism at the Service of the Unity of International Law. European Journal of International Law Review, 21, 585-604.

Mac-Gregor, E. (2014). Las siete principales líneas jurisprudenciales de la CIDH Interamericana de Derechos Humanos aplicable a la justicia penal. Revista IIDH, 59, 29-118.

Malarino, E. (2010). Activismo judicial, punitivización y nacionalización. Tendencias antidemocráticas y antiliberales de la Corte Interamericana de Derechos Humanos. Sistema Interamericano de Protección de los Derechos Humanos y Derecho Penal Internacional (pp. 25-62). Berlín: Konrad-Adenauer-Stiftung.

Melish, T. (2008). The Inter-American Commission on Human Rights: Defending Social Rights through Case-based Petitions. SSRN. En M. Langford (ed.), Social Rights Jurisprudence. Energing Trends in Comparative and International Law (pp. 207-274). Cambridge: Cambridge University Press.

Neuman, G. (2008). Export, and Regional Consent in the Inter-American Court of Human Rights. The European Journal of International Law, 19 (1), 101-123.

Paul, A. (2014). Decision-Making Process of the Inter-American Court: An Analysis Prompted by the in Vitro Fertilization Case. ILSA Journal of International and Comparative Law, 21 (1), 87-130. 
Quispe, F. (2010). lus cogens en el Sistema Interamericano: Su relación con el debido proceso. Revista de Derecho, 34, 42 -78.

Ronconi, L. (2016). Mucho ruido y pocos... DESC. Análisis del caso Gonzales Lluy y Otros contra Ecuador de la CIDH Interamericana de Derechos Humanos. Anuario de Derechos Humanos, 12, 119-131.

Scovazzi, T. y Citroni G. (2007). The struggle against enforced disappearance and the 2007 United Nations convention. Leiden: Martinus Hijhoff Publishers.

\section{Sentencias}

Corte Europea de Derechos Humanos (1986). Johnston and others Vs. Ireland. Sentencia de 18 de diciembre de 1986. Serie A No. 112.

CIDH (1999a) "Niños de la Calle" (Villagrán Morales y otros) Vs. Guatemala. Sentencia de 19 de noviembre de 1999. Serie C No. 63.

- (2001). Baena Ricardo y otros Vs. Panamá. Fondo, Reparaciones y Costas. Sentencia de 2 de febrero de 2001. Serie C No. 72.

- (2003). "Cinco Pensionistas" Vs. Perú. Fondo, Reparaciones y Costas. Sentencia de 28 de febrero de 2003. Serie C No. 98.

- (2004a) Carpio Nicolle y otros Vs. Guatemala. Fondo, Reparaciones y Costas. Sentencia de 22 de noviembre de 2004. Serie C No. 117.

- (2004b) Masacre Plan de Sánchez Vs. Guatemala. Reparaciones y Costas. Sentencia de 19 de noviembre de 2004. Serie C No. 116.

- (2004c). "Instituto de Reeducación del Menor" Vs. Paraguay. Excepciones Preliminares, Fondo, Reparaciones y Costas. Sentencia de 2 de septiembre de 2004. Serie C No. 112.

- (2005a) Masacre de Mapiripán Vs. Colombia. Fondo, Reparaciones y Costas. Sentencia de 15 de septiembre de 2005. Serie C No. 134.

- (2005b). Huilca Tecse Vs. Perú. Fondo, Reparaciones y Costas. Sentencia de 3 de marzo de 2005. Serie C No. 121.

- (2006) La Cantuta Vs. Perú. Sentencia sobre fondo, reparaciones y costas de 29 de noviembre de 2006. Serie C No 162.

- (2008a) Apitz Barbera y otros Vs. Venezuela. Excepción Preliminar, Fondo, Reparaciones y Costas. Sentencia de 5 de agosto de 2008. Serie C No. 182.

- (2008b) Tiu Tojín Vs. Guatemala. Fondo, Reparaciones y Costas. Sentencia de 26 de noviembre de 2008. Serie C No. 190.

- (2009a). Kawas Fernández Vs. Honduras. Fondo, Reparaciones y Costas. Sentencia de 3 de abril de 2009. Serie C No. 196.

- (2009b). Rios y otros Vs. Venezuela. Excepciones Preliminares, Fondo, Reparaciones y Costas. Sentencia de 28 de enero de 2009. Serie C No. 194.

- (2010a) Chitay Nech y otros Vs. Guatemala. Excepciones Preliminares, Fondo, Reparaciones y Costas. Sentencia de 25 de mayo de 2010. Serie C No. 212.

- (2010b) Ibsen Cárdenas e Ibsen Peña Vs. Bolivia. Fondo, Reparaciones y Costas. Sentencia de 1 de septiembre de 2010. Serie C No. 217.

- (2011) Contreras y otros Vs. El Salvador. Fondo, Reparaciones y Costas. Sentencia de 31 de agosto de 2011. Serie C No. 232.

- (2012a) Forneron e hija Vs. Argentina. Fondo, Reparaciones y Costas. Sentencia de 27 de abril de 2012. Serie C No. 242. 
- (2012b) Furlan y Familiares Vs. Argentina. Excepciones Preliminares, Fondo, Reparaciones y Costas. Sentencia de 31 de agosto de 2012. Serie C No. 246.

- (2012c) Pueblo Indigena Kichwa de Sarayaku Vs. Ecuador. Fondo y reparaciones. Sentencia de 27 de junio de 2012. Serie C No. 245.

- (2012d). Artavia Murillo y otros Vs. Costa Rica. Excepciones Preliminares, Fondo, Reparaciones y Costas. Sentencia del 28 de noviembre de 2012. Serie C, No. 257.

- (2012e). Masacres de El Mozote y lugares aledaños Vs. El Salvador. Fondo, Reparaciones y Costas. Sentencia de 25 de octubre de 2012. Serie C No. 252.

- (2013a) J. Vs. Perú. Excepción Preliminar, Fondo, Reparaciones y Costas. Sentencia de 27 de noviembre de 2013. Serie C No. 275.

- (2013b). García Lucero y otras Vs. Chile. Excepción Preliminar, Fondo y Reparaciones. Sentencia de 28 de agosto de 2013. Serie C No. 267.

- (2015). Gonzales Lluy y otros Vs. Ecuador. Excepciones Preliminares, Fondo, Reparaciones y Costas. Sentencia de 1 de septiembre de 2015. Serie C No. 298.

\section{Opiniones consultivas}

CIDH (1999). El derecho a la información sobre la asistencia consular en el marco de las garantías del debido proceso legal. Opinión Consultativa OC-16/99 de 1 de octubre de 1999. Serie A No. 16.

- (2003). Condición Jurídica y Derechos de los Migrantes Indocumentados. Opinión Consultiva OC-18/03 del 17 de septiembre de 2003. Serie A No. 18 